\title{
Uso da Contabilidade de Custos Ecológicos para Melhoria de um Projeto de Produção Enxuta
}

\section{RESUMO}

Marco Antonio Cortellazzi Franco ${ }^{1}$

Fabiana Giusti Serra ${ }^{2}$

Felipe Araújo Calarge ${ }^{3}$

José Carlos Curvelo Santana ${ }^{4}$

As práticas da produção enxuta foram amplamente disseminadas na indústria automobilística e têm como objetivo eliminar os desperdícios e reduzir custos na produção. Como resultado de seu sucesso na manufatura, esse conceito expandiu-se para a área administrativa e atualmente é aplicado também na redução dos desperdícios ambientais com o nome de produção enxuta verde. A Contabilidade de Custos Ecológicos (CCE) é um método que pode ser empregado para as empresas mostrarem que a remediação dos impactos ambientais e sociais causados por suas atividades pode ser feita de forma a não comprometer seus resultados econômico-financeiros. O objetivo deste trabalho foi estudar a implantação conjunta das práticas da produção enxuta e da CCE em uma indústria automobilística brasileira, utilizando para tanto um estudo de caso único durante um período de sete anos. Os resultados obtidos mostraram que foi possível mesclar as técnicas de produção enxuta com a CCE para minimizar os impactos sociais e ambientais provocados pela empresa usando soluções economicamente sustentáveis. Verificou-se que a empresa obteve uma redução no consumo de energia elétrica de 2.803.000 kW/ano e de 68,7 t/ano nas emissões de $\mathrm{CO}_{2}$, equivalentes, na época, a uma redução de R \$ 121.000,00/ano nos custos.

Palavras-Chave: Contabilidade de custos ecológicos; produção enxuta; créditos de carbono; desenvolvimento sustentável; processos ecologicamente corretos.

\section{Use of Ecological Cost Accounting to Improve a Lean Production Project}

\begin{abstract}
Lean production practices were widely disseminated in the automotive industry and aim to eliminate waste and reduce costs in production. As a result of its success in the manufacture, this concept expanded into the administrative area, and currently is applied in reducing environmental waste with lean green name. The Ecological Cost Accounting (ECA) is a
\end{abstract}

\footnotetext{
1 Engenheiro Industrial Mecânico graduado pela Faculdade de Engenharia Industrial (FEI), atual Centro Universitário da FEI (1972), Mestre em Engenharia de Produção pela Universidade Nove de Julho (2015), Pósgraduado em Administração da Produção e Operações Industriais pela Escola de Administração de Empresas de São Paulo da Fundação Getúlio Vargas (1975).

2 Mestra em Engenharia de Produção pela Universidade Nove de Julho, com o tema de sustentabilidade empresarial (2015). Engenheira mecânica pelo Centro Universitário da FEI (2001). Professora no curso de graduação em Engenharia de Produção no IMT. Professora do curso de Engenharia de Produção e na MBA em Lean Manufacturing da UNIP. Professora convidada no curso de Administração da FECAP.

${ }^{3}$ Possui graduação em Engenharia Mecânica (1984) e Ciências Econômicas (1988), Mestrado em Engenharia Mecânica (1993) e Doutorado em Engenharia Mecânica (2000) pela Universidade Estadual de Campinas UNICAMP. Conduziu Pós Doutoramento junto à Universidad Complutense de Madrid (2006).

4 Possui graduação em Química Industrial pela Universidade Federal de Sergipe (1999), mestrado em Engenharia Química pela Universidade Estadual de Campinas (2003) e doutorado em Engenharia Química pela Universidade Estadual de Campinas (2006). Atualmente é professor do Programa de Pós-Graduação em Engenharia de Produção da Universidade Nove de Julho.
} 
method that can be used to show that the remediation of social and environmental impacts caused by companies' activities can be done in a way that does not compromise their economic results. This work aimed to study the joint deployment of lean production practices and ECA in a Brazilian auto industry using a single case study over a period of seven years. The results showed that it was possible to merge the lean production techniques with the method of ECA in order to minimize social and environmental impacts of the enterprise, using economically sustainable solutions. It was found that the company obtained a reduction in electricity consumption of 2,803 thousand $\mathrm{kW} /$ year and 68.7 tons/year of $\mathrm{CO}_{2}$ emissions, equivalent in time to a reduction in costs of $\mathrm{R} \$ 121,000.00 /$ year.

Key Words: Ecological cost accounting; lean manufacture; carbon credit; sustainable development; eco-friend process. 


\section{USO DA CONTABILIDADE DE CUSTOS ECOLÓGICOS PARA MELHORIA DE UM PROJETO DE PRODUÇÃO ENXUTA}

\section{INTRODUÇÃO}

O setor automobilístico brasileiro, especialmente a indústria de autopeças, iniciou suas atividades em 1950. Em 2003, já eram 29 montadoras, 500 fornecedores de autopeças espalhados em 10 estados brasileiros com uma capacidade instalada de 4,3 milhões de veículos por ano. Esses números colocaram o Brasil na $6^{\text {a }}$ posição do ranking mundial de fabricantes de veículos ultrapassando países como Espanha e França (ANFAVEA, 2018). A indústria automobilística brasileira responde por aproximadamente $15 \%$ do PIB da indústria brasileira segundo dados do IBGE (2018) e é responsável pela geração de 1,5 milhões de empregos diretos e indiretos.

As práticas de produção enxuta são amplamente usadas pela indústria automobilística brasileira, mas, dentro do cenário da indústria nacional, poucos projetos abordam as questões ambientais como vários seguimentos industriais no Mundo. O desperdício ambiental é de fácil medição devido à sinergia entre as práticas de produção enxuta e o desempenho ambiental; ambos levam à redução dos desperdícios e dos impactos ambientais além de influenciarem nos lucros das empresas. As práticas da produção enxuta são mais do que uma coincidente relação de causa-efeito, representam mais um passo em direção à evolução natural para a produção enxuta verde, pois são práticas sinergéticas que combinam o gerenciamento das operações com o do meio ambiente (PAMPANELLI et al., 2014).

Os autores supracitados definem desperdícios como sendo a superprodução; o inventário (tempo de material parado no estoque); a movimentação humana desnecessária; a espera (recursos parado); o transporte de materiais; super processamento e o retrabalho (produzir sem qualidade).

Geralmente, quando se reconhecem os desperdícios ambientais, a produção enxuta é chamada de produção enxuta verde (lean green production). Porém, as práticas de produção enxuta verde podem entrar em conflito com os anseios da empresa, dessa forma, é fundamental encontrar um ponto de equilíbrio para garantir, ao mesmo tempo, os resultados em termos econômicos, ecológicos e sociais (MIRANDA et al., 2018; PASSARINI et al., 2014). Neste sentido Vinodh et al. (2011) apresentaram dois novos desperdícios: o desperdício humano (má utilização do recurso humano) e o desperdício ambiental (utilização desnecessária ou excessiva de recursos e contaminação do meio ambiente).

De acordo com Benvenga et al. (2016), Miranda et al. (2018) e Silva Filho et al. (2018) o efeito do aquecimento global é um fator de discussão sobre sustentabilidade pelo alerta à sociedade quanto a necessidade das empresas adotarem atitudes adequadas em relação ao meio ambiente, dessa forma, as empresas mostrariam sua integridade ambiental, social e econômica. Para serem sustentáveis, as empresas devem reduzir os impactos ambientais e sociais devidos às suas atividades de forma economicamente viável, através de abordagens preventivas de acordo com os princípios de melhoria contínua.

Uma maneira para mensurar e integrar os custos ecológicos internos e externos dos processos produtivos e demonstrar a contribuição das empresas para a sustentabilidade é o cálculo da Contabilidade de Custos Ecológicos (GIRAÇOL et al., 2011).

Assim, este trabalho teve como objetivo aplicar as práticas de produção enxuta junto com a contabilidade de custo ecológico, como uma nova abordagem da produção enxuta verde. O estudo de caso ocorreu em uma indústria automobilística mineira, de forma a verificar seus ganhos nas dimensões social, ecológica e econômica. 


\subsection{Produção enxuta verde}

A Produção Enxuta é uma iniciativa adotada pela indústria do mundo todo para manter-se em um ambiente crescente de competitividade mundial e com o objetivo de redução de custo através da eliminação do que o cliente não está disposto a pagar, ou seja, o que não agrega valor (RAHANI e AL-ASHRAF, 2012).

Indústrias que adotaram as práticas de produção enxuta são líderes em eficiência na produção em diferentes regiões do planeta. A produção enxuta é considerada há décadas a melhor maneira de gerenciar uma indústria manufatureira (PAMPANELLI et al., 2014).

A produção enxuta é um sistema de gerenciamento de produção desenvolvido pela Toyota Motor Company (TMC), montadora de veículos japonesa para a maximização da utilização dos recursos sejam eles, humanos, maquinários, estruturais e logísticos, entre outros, e reduzir custos (PINTO, 2012). Esses desperdícios ficaram conhecidos como os 3M da manufatura e foram definidos por Stone (2012) como:

- MUDA Desperdício, ou também a não agregação de valor na operação;

- MURA Variação na operação e

- MURI Sobrecarga do operador ou máquina.

Os desperdícios foram definidos por Pampanelli et al. (2014), Slack et al. (2009) e Vinodh et al. (2011), entre outros, como:

1 Superprodução: Desperdício de produzir mais do que a demanda.

2 Inventário: Desperdício de tempo de material parado no estoque.

3 Movimentação: Desperdício de movimentos humanos desnecessários.

4 Espera: Desperdício de recursos parado aguardando sequência.

5 Transporte: Desperdício de transporte de materiais.

6 Super processamento: Desperdício de excesso de processos.

7 Retrabalho: Desperdício de produzir sem qualidade.

8 Humano: Desperdícios da má utilização do recurso humano;

9 Ambiental: Utilização desnecessária ou excessiva de recursos, bem como substâncias liberadas no ar, ou contaminação de solo ou comprometimento a saúde ou ao meio ambiente.

Para a Environmental Protection Agency (EPA) (2018), empresas que adotam estratégias ecológicas obtêm resultados positivos como a redução do impacto ambiental, de forma a reduzir ou eliminar desperdícios ambientais como água, energia, ar, resíduos sólidos e resíduos perigosos. Assim pode-se considerar que o desperdício ambiental ocorre quando uma empresa usa recursos para prover produtos ou serviços para clientes sem quantificar o impacto e o desperdício ambiental associado (PAMPANELLI et al., 2014).

As práticas da produção enxuta são baseadas na agregação de valor e identificação de desperdícios nos processos enquanto as práticas da produção enxuta verde identificam e quantificam a extração de matéria-prima e a disposição dos resíduos de forma a mostrar o que está além da capacidade da natureza de absorver (PAMPANELLI, 2014).

Em linha com a identificação, controle e redução dos desperdícios ambientais, foi desenvolvido por Ahi e Searcy (2013) um estudo que relaciona a redução dos desperdícios ambientais com a produção enxuta a qual se denominou como produção enxuta verde. A produção enxuta verde é tida como sendo a aplicação de práticas de produção enxuta com o objetivo de reduzir desperdícios ambientais em processo de manufatura (GALEAZZO et al. , 2014).

A produção enxuta verde é uma extensão natural da produção enxuta uma vez que suas práticas são verdes sem a explícita intenção de ser. Uma empresa com produção enxuta pode facilmente ser uma empresa com produção enxuta verde devido ao fato de o objetivo de 
ambas as práticas serem a eliminação de desperdício (PAMPANELLI et al., 2014).

\subsection{Contabilidade de custos ecológicos}

Os custos ambientais são definidos pela EPA (2018) como aqueles que têm impacto financeiro direto nas empresas e custos às pessoas e sociedade. A contabilidade de custo ecológico provoca debates na comunidade científica desde 1970 para estruturar a noção da contabilidade ecológica e posteriormente, a partir de 1990, a formalização da sua instrumentalização (ALCOUFFE et al., 2010).

Vários autores abordaram a aplicação da contabilidade de custo ecológico em diferentes segmentos: públicos, privados, manufatureiros e extrativistas em diversos países, porém, no decorrer deste trabalho não foram encontrados estudos dessa natureza para a indústria automobilística brasileira (CHRIST; BURRITT, 2015; DERCHI et al., 2013; GUNARATHNE et al., 2016; MAAS et al., 2016; NAKAJIMA, 2010; SCHALTEGGER, 2008).

Uma das formas de amortizar o custo ecológico é pela venda de créditos de carbono, um mercado que surgiu em dezembro de 1997 quando foi assinado o Protocolo de Kioto que priorizava uma redução de 5,2\% da emissão de gases entre 2008 e 2012 (GIRAÇOL et al., 2011). Além disso, para evitar comprometer a economia dos países participantes, o Protocolo de Kioto possibilitou a compra de créditos de carbono de outros países baseado em projetos de eliminação ou redução de emissões. Essas negociações são atualmente praticadas por países como Canadá, Dinamarca, Alemanha, Japão, Suécia e Noruega (GIRAÇOL et al., 2011).

No mercado Europeu, os créditos de carbono eram comprados por aproximadamente US\$ 9.25/t (GIRAÇOL et al., 2011). A contabilidade de custo ecológico tem sido estudada de forma abrangente a partir da assinatura do Protocolo de Kioto, por vezes correlacionando as práticas de produção enxuta verde, ao atendimento a legislações locais e pressões dos stakeholders.

$\mathrm{Na}$ Indonésia, a segunda maior empresa produtora de borracha do mundo em 2010 com aproximadamente $28 \%$ da produção mundial, teve o seu fluxo de extração de material e produção de borracha natural avaliado pelo mapeamento da cadeia de valor (VSM) e pelos nove desperdícios para a quantificação da melhoria do desempenho ecológico e econômico. Foram contabilizados uma redução de $1830 \mathrm{~kW} / \mathrm{h}$ no consumo de energia, redução de 2769,17 $\mathrm{km}$ no transporte e em consequência a redução na emissão de $3094.3 \mathrm{~kg} \mathrm{de} \mathrm{CO}_{2}$ ao ano (MARIMIN et al., 2014).

Pereira (2011) avaliou através dos relatórios contábeis de 167 usinas sucroalcooleiros do estado de São Paulo seus posicionamentos quanto à gestão organizacional direcionada ao desenvolvimento sustentável nas dimensões econômica, ecológica, tecnológica e humana. Os resultados mostraram que $87 \%$ das empresas divulgavam programas socioambientais em seus relatórios. $\mathrm{O}$ assunto sustentabilidade foi o que mais se destacou em aproximadamente $50 \%$ das usinas pesquisadas e a cogeração de energia em 10\%, indicando a utilização de créditos de carbono através da contabilidade de custos ecológicos.

Passarini et al., (2014) aplicaram a contabilidade de custo ecológico na gestão dos resíduos de esgoto e da construção civil da cidade de Campinas, S.P. Esses resíduos foram tratados de forma a gerarem adubos para os solos pobres e água de reuso. Com o uso do adubo, a qualidade do solo aumentou em $11,11 \%$ e as sementes irrigadas com a água de reuso tiveram um aumento de $6 \%$ no tamanho das sementes de feijão.

Rosa et. al., (2013) aplicaram a contabilidade de custo ecológico em uma empresa do segmento têxtil no Estado de São Paulo pela reutilização da água de rejeito no processo 
produtivo e gerou ganhos econômicos de $\mathrm{R} \$ 21.908,75$ por mês, ganhos ecológicos por deixar de consumir água e descartar poluentes e ganhos sociais através da imagem de uma empresa que não polui os rios.

\section{METODOLOGIA}

\subsection{Descrição da empresa usada no estudo de caso}

O Fornecedor A é um fabricante nacional de rodas de alumínio para a indústria automobilística, instalado há 35 anos na região Sudeste do Brasil. Seus principais clientes são General Motors, Honda, Toyota do Brasil e Mitsubishi entre outras montadoras. Tem uma capacidade instalada de 2.500 .000 rodas por ano. O fluxo de seu processo de manufatura compreende a fundição do alumínio, usinagem, pintura e termina na embalagem. Em uma única unidade fabril, eram empregadas 357 pessoas diretas, operando em dois turnos de trabalho.

Devido à concorrência mundial no mercado de rodas, principalmente com os chineses, o Fornecedor A viu-se obrigado a reduzir custos para manter-se competitivo e, por ser um dos pontos principais a produção enxuta, iniciou sua implantação em 2006.

Os dados do Fornecedor A estudados neste trabalho foram obtidos no ano de 2008, durante os sete meses da aplicação da atividade de Jishuken no fornecedor de rodas para os veículos Corola, Fielder e Hilux.

Marksberry et al. (2010) descreveu em seu estudo que o Jishuken é uma atividade de chão de fábrica para a redução de desperdícios na cadeia de fornecedores utilizada pela Toyota Motor Corporation.

\subsection{Procedimentos para a aplicação do projeto}

O método de pesquisa escolhido foi o estudo de caso, para Yin (2010) o estudo de caso tem um caráter empírico e como objetivo investigar um determinado fenômeno que ocorre na realidade, mas que não está claramente definido, possibilitando o desenvolvimento de novas teorias, com base nas evidências observadas. $\mathrm{O}$ estudo de caso enriquece não só a teoria, mas também as próprias pesquisas pela realização de estudos de campo e também por estar exposto aos problemas reais, o que permite ter uma visão criativa das pessoas em todos os níveis das organizações e em contextos variados dos casos, inclusive do investigador, se tem benefícios com a realização da pesquisa.

Para a implantação do projeto de produção enxuta foi utilizada a seguinte sequência (DÜES et al. 2013):

- Inscrição do Fornecedor A no cronograma das atividades de produção enxuta com o suporte da Toyota do Brasil em sua planta. O Fornecedor A foi informado da necessidade de disponibilizar mão de obra durante a atividade.

- Planejamento de visitas para a planta do Fornecedor A:

- $1^{\text {a }}$ Visita: Definição do processo produtivo que deveria ser priorizado através de indicadores de qualidade e de eficiência, visita ao chão de fábrica para conhecer o fluxo do processo e fluxo do material, identificação das ineficiências do processo e analise dos indicadores de produção, definição da "situação antes" da implantação das práticas de produção enxuta, escolha dos indicadores a serem acompanhados e seus objetivos;

- $2^{a}$ Visita: Visita ao chão de fábrica para validação das práticas de produção enxuta utilizadas. Nesta visita todas as práticas de produção enxuta deveriam 
estar definidas e prontas para serem implantadas, foram definidas as metas da "situação depois". Nesta etapa poderia haver as alterações de fluxo de processo, alteração de operações, alteração de operadores, alteração de arranjo das células de produção, entre outras. Nesta etapa poderia ser analisado o trabalho padronizado, os desperdícios a serem eliminados, o Just in time (JIT) e o fluxo de agregação de valor do produto (VSM).

- $3^{\text {a }}$ Visita: Visita ao chão de fábrica para a verificação da adesão e dos resultados da implantação das práticas de produção enxuta. Nesta etapa foram calculados os resultados obtidos pela implantação das práticas de produção enxuta definidos para a "situação depois".

- Resultados e premiação: Subtração dos indicadores da "situação antes" e "situação depois" de forma a evidenciar a redução nos índices dos indicadores definidos, através da Equação 1.

- Premiação dos fornecedores que melhor usaram as práticas de Produção Enxuta na Convenção Anual.

- Todo o procedimento para a implantação da produção enxuta demorou sete meses para ser concluído.

Resultados obtidos = "situação antes" - "situação depois"

As equações 2 e 3 mostram as diferenças entre os consumos de energia (CET) e a redução dos custos com a energia.

Redução Energia $_{\text {ano }}(\mathrm{kW})=\mathrm{CET}_{\text {antes }}-\mathrm{CET}_{\text {depois }}$

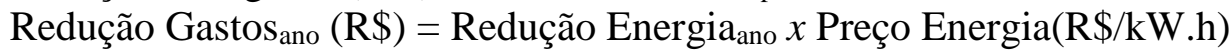

\subsection{Procedimentos para a implantação da contabilidade de custo ecológico}

Vários autores consideram a utilização de estágios de sustentabilidade como a melhor estratégia para alcançar a CCE (GIRAÇOL et al., 2011; PASSARINI et al., 2014). Os passos que foram utilizados para a implantação da contabilidade de custos ecológicos foram (SILVA FILHO et al., 2018):

- Estágio 1: "situação antes" do Fornecedor A em uma condição não sustentável onde muitos dos impactos ambientais não eram identificados e controlados e haviam desperdícios no processo;

- Estágio 2: foram implantadas as práticas de produção enxuta e seus resultados medidos em redução no consumo de energia elétrica;

- Estágio 3: com a produção estabilizada já era possível coletar os ganhos ecológicos;

- Estágio 4: nesse estágio o Fornecedor A seria reconhecido como uma empresa sustentável, pelo balanço dos resultados da contabilidade dos custos ecológicos, e gerando créditos para si mesmo.

Cada estágio consistia nos graus de evolução que o Fornecedor A poderia alcançar ao seu final. Assim, o primeiro estágio consistiu nas atitudes em identificar seus impactos e definir ações para minimizá-los. O segundo estágio, em apresentar os primeiros resultados da redução de impactos ambientais para a sociedade. Já o terceiro estágio consistiu na coleta de ganhos ecológicos de forma a reduzir os custos ambientais e o quarto e último estágio no atendimento das demandas das dimensões econômica, social e ambiental.

Para contabilizar os custos ecológicos alcançados pela implantação das práticas de produção enxuta no Fornecedor A, foi aplicada a Calculadora Oficial de Crédito de Carbono obtida no site do Programa Brasileiro GHG Protocol, que tem como principal objetivo o inventário dos gases de efeito estufa, pela mensuração de suas emissões. Os passos para monetizar os ganhos oriundos da atividade do projeto de produção enxuta no ano de 2008 do 
Fornecedor A, foram:

a) Cálculo do consumo de energia elétrica dos tornos e lixadeiras na "situação antes" e "situação depois" do aumento da demanda de produção. Esse cálculo foi feito da seguinte forma:

i. Levantamento do tempo de torno e lixadeira ligada para atender a demanda de produção.

ii. Levantamento junto a Engenharia Industrial qual era o consumo em $\mathrm{kW} / \mathrm{h}$ dos tornos e lixadeiras junto aos fabricantes dos mesmos.

iii. Aplicação da Equação 2 e 3 do consumo de energia elétrica dos tornos e lixadeiras por turno

b) Utilização da calculadora de crédito de carbono usando como dados de entrada o consumo mensal de energia elétrica na "situação antes" e "situação depois". Coleta do consumo médio mensal de energia elétrica $(\mathrm{kW} / \mathrm{h})$ entre os anos de 2008 a 2014 para a "situação antes" e "situação depois". A Figura 1 mostra a planilha Excel onde se encontra a calculadora oficial de crédito de carbono disponível no site para download.

Figura 1 - Calculadora oficial de crédito de carbono do programa brasileiro GHG Protocol.

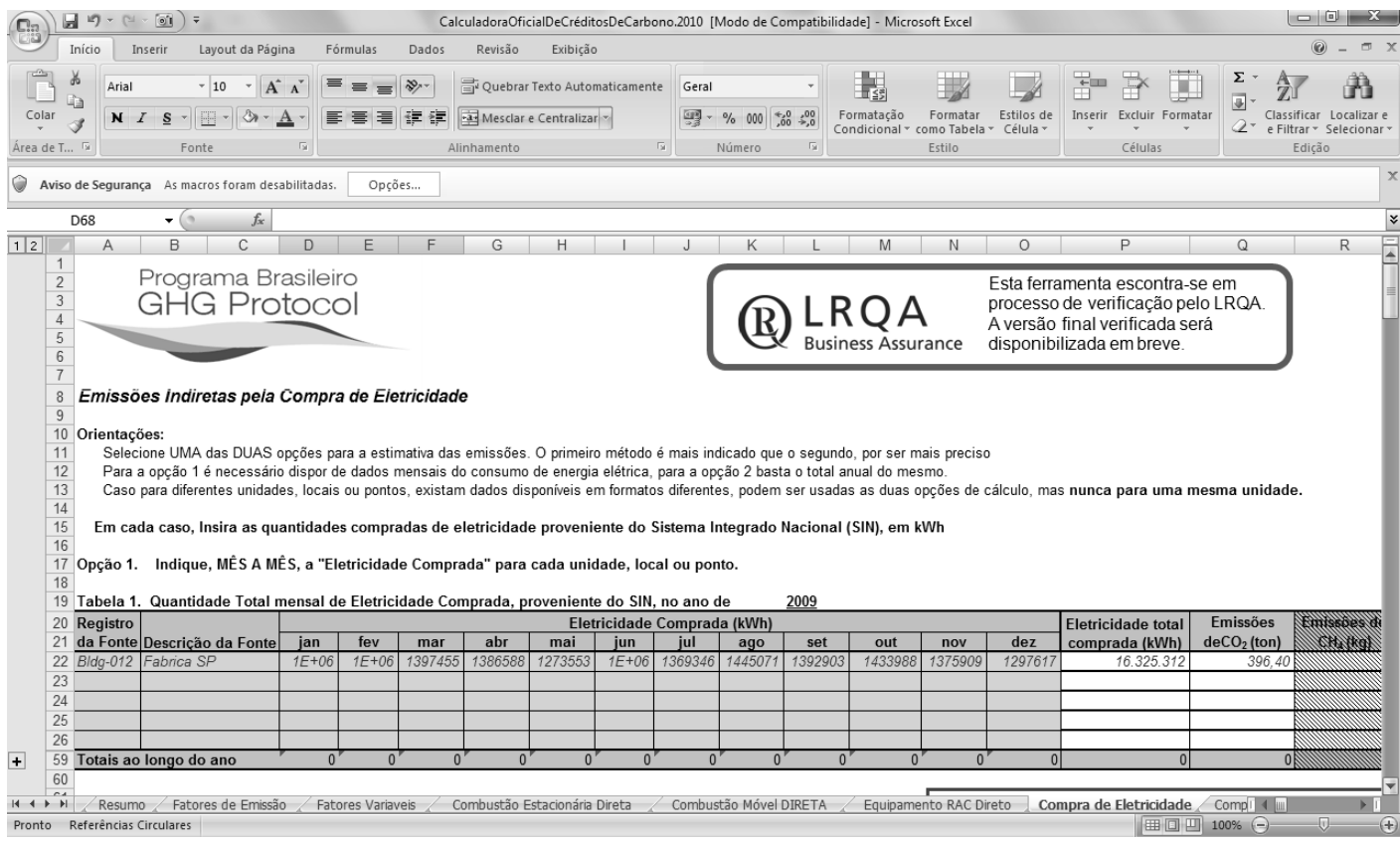

Fonte: http://www.ghgprotocolbrasil.com.br/ferramenta-de-calculo.

\section{RESULTADOS E DISCUSSÕES}

\subsection{Resultados do projeto de produção enxuta}

Os processos de manufatura do Fornecedor A compreendiam fundição, usinagem, pintura e embalagem e o processo gargalo era a usinagem, com um tempo de produção que ultrapassava os 9 segundos/peça, que, além de gerar espera entre os processos gerava hora extra para atender a demanda. A seguir relacionou-se o que deveria ser reduzido ou eliminado:

- Variação de tempo de ciclo entre os operadores;

- Variação do tempo de processamento dos tornos e lixadeiras;

- Desperdícios de espera entre os processos; 
- Inspeções que não agregam valor.

Nas visitas para acompanhamento da produção foi possível levantar todos os indicadores e entender qual a situação do Fornecedor A em termos de fluxo de produção, aderência ao trabalho padronizado e movimentos dos operadores e propor alterações para alcançar a "situação futura" através do Value Stream Map (VSM).

As práticas de produção enxuta aplicadas ao processo de usinagem tiveram como objetivo a redução dos desperdícios, para identifica-los foram feitas visitas para acompanhamento de uma hora da produção quando foram propostos os pontos em que as práticas de produção enxuta deveriam ser aplicadas para aumentar a eficiência do processo:

- Revisão do trabalho padronizado e treinamento dos operadores. Os operadores não mantinham uma sequência repetida de produção, andando para puxar as rodas e para procurar a lixadeira;

- Movimentos repetitivos: posições não ergonômicas e o carregamento de pesos deveriam ser eliminados ou reduzidos ao máximo possível;

- Trabalho padronizado dos operadores: foram otimizadas as operações criando um fluxo de agregação de valor do produto e dos operadores de forma a atender o prazo, com segurança para os operadores e com a qualidade assegurada;

- Redução de 51 segundos do tempo de ciclo do trabalho padronizado dos operadores;

- A revisão do tempo de processamento dos tornos e lixadeiras dos operadores. Não havia uma padronização de tempo de torneamento e lixamento interferindo no tempo de ciclo e na qualidade do produto;

- Desperdício de super processamento, por exemplo, existia uma dependência do operador com o número de passagens de lixa, a sequência das lixas e por onde iniciar;

- Estudo feito com os departamentos de engenharia industrial e da qualidade para a determinação da sequência de produção mais enxuta, de forma a aproveitar ao máximo o tempo dos tornos e lixadeiras, garantir a qualidade e a sequência de operação;

- Redução do desperdício de super processamento: foram devolvidos para o processo 182 segundos, além do ganho em qualidade;

- Critérios de aceitação da qualidade: foram padronizados de forma a não depender mais da subjetividade do operador;

- O desperdício de espera estava evidente durante a visita à usinagem, pois um operador aguardava a entrega das rodas para usinagem o que impactava o trabalho do segundo operador que já havia produzido e que estava na esteira aguardando pelas rodas;

- Abastecimento de entrada de rodas desbalanceado, uma vez que para o cálculo de rotas de abastecimento feito pelo departamento de logística, a eficiência seria de $85 \%$, onde na verdade era de $64 \%$;

- Desperdício de espera foi facilmente reduzido, pois houve um aumento na frequência de abastecimento das rodas, de forma a garantir que o fluxo de agregação de valores não parasse;

- Não foi possível eliminar o desperdício de espera já que o tempo de torno e da lixadeira de um operador ser maior do que o do outro, gerando alguns segundos de desperdício ainda.

- As inspeções não agregam valor ao produto, isso quer dizer que devem ser eliminadas pelo fato do cliente não querer pagar. As inspeções são um sinal de que os processos anteriores não conseguem garantir a qualidade sendo necessária a colocação de barreiras para que o problema não chegue ao próximo processo ou ao cliente; 
- Inspeções incorporadas aos processos como forma de garantir a excelência na execução, evitando que as peças sigam para os próximos processos com problemas na qualidade;

- Coleta dos indicadores de qualidade dos últimos três meses: verificou-se que $80 \%$ dos problemas estavam relacionados ao torneamento fora do padrão e ao lixamento, ou seja, a necessidade da inspeção era provocada pela falta de estudos sobre a sequência de torneamento e lixamento que garantissem agregação de valor e qualidade;

- Os $20 \%$ restantes estavam relacionados a avarias no transporte, sujeira incrustada e falta de processamento. Esses problemas eram causados pelos movimentos desnecessários dos operadores, provocavam batidas e riscos, as incrustações eram provocadas pela falta de padronização da sequência de torneamento, ou seja, torneando sobre cavaco;

- Foram eliminados do tempo de ciclo dos operadores 17 segundos.

Com a redução dos desperdícios de movimentação, de super processamento e espera, a eficiência da usinagem passou de $63 \%$ para $74 \%$ evitando a adoção de um novo turno de trabalho e a necessidade de horas extras.

Ao término da atividade de projeto (outubro de 2008), o Fornecedor A consolidou seus ganhos de aumento de eficiência, ou seja: redução no tempo de processamento das peças pelos operadores de $32,5 \%$, redução no tempo de ciclo dos tornos de $83,5 \%$, redução do tempo de ciclo de uma das lixadeiras em $80 \%$, redução da inspeção em 35,5\% e redução no desperdício de espera de 70,5\% sem nenhuma variação no trabalho padronizado.

Foi possível identificar, que mesmo tendo sido considerado um trabalho com aplicação das práticas da produção enxuta, não foram observadas possibilidades de outros ganhos associados como a redução no consumo de energia elétrica, a contabilidade de custos ecológicos ou melhoria na qualidade de vida da sociedade ao redor do Fornecedor A de forma a atender as três dimensões da sustentabilidade.

\subsection{Aplicação da contabilidade de custo ecológico}

Para a aplicação da contabilidade de custo ecológico seguiu-se as seguintes etapas:

Cálculo do consumo de energia elétrica diário dos tornos e lixadeiras na "situação antes" e "situação depois" do aumento da produção; resultado do consumo de energia elétrica dos tornos e lixadeiras na "situação antes"; consumo de energia elétrica dos tornos e lixadeiras na "situação depois"; cálculo mensal de consumo de energia elétrica dos tornos e lixadeiras na "situação antes" e "situação depois" do aumento da demanda de produção; consumo de energia elétrica dos tornos e lixadeiras e a utilização da calculadora de crédito de carbono para o calculo das emissões antes e depois do projeto.

Baseados no modelo da contabilidade de custos ecológicos foram analisados os dados do Fornecedor A quanto aos resultados obtidos na implantação das práticas de produção enxuta nos tornos no ano de 2008, descritos na Tabela 1.

Tabela 1. Consumo e custos diários dos tornos para atender a demanda de peças

\begin{tabular}{llll}
\hline Tornos & Peças diárias & Energia diária $(\mathbf{k W})$ & Demanda diária $(\mathbf{R} \mathbf{)})$ \\
\hline Situação antes & 448 & 507,7 & 25,1 \\
Situação depois & 582 & 434,5 & 21,5 \\
\hline
\end{tabular}

Fonte: Os autores

A análise da Tabela 1 mostra que apesar da produção ter aumentado em $24 \%$, as práticas de produção enxuta implantadas, como a padronização das operações e a redução dos 
desperdícios de movimentação, de espera e de super processamento proporcionaram em uma diminuição de $12 \%$ no consumo de energia elétrica.

Com o resultado alcançado com as práticas da produção enxuta foi evidenciada uma diminuição de consumo de energia para atendimento a demanda diária de $15 \%$ descritos na Tabela 2.

Tabela 2 - Consumo reduzido de energia elétrica nos tornos após a aplicação do projeto

\begin{tabular}{lll}
\hline Tornos & Consumo energético (kW/Peça) & Consumo anual (kW/Ano) \\
\hline Situação antes & 0,5 & 134041,6 \\
Situação depois & 0,3 & 114723,8 \\
\hline
\end{tabular}

Fonte: Os autores

O custo da energia elétrica industrial da CEMIG em 2008 era de $\mathrm{R} \$ 0,40$ por $\mathrm{kW} / \mathrm{h}$ e o consumo dos tornos foi calculado pela engenharia de processos do Fornecedor A nas situações antes e depois considerando-se os modelos dos tornos e sua vida útil no período estudado. Consequentemente houve uma redução no valor na conta de energia elétrica como foram descritos na Tabela 3 os valores financeiros acumulados no período de um ano.

Tabela 3 - Custos da energia para produção das peças nos tornos

\begin{tabular}{lll}
\hline Tornos & $\mathbf{R} \$ \mathbf{k W} / \mathbf{P e c ̧ a}$ & $\mathbf{R}$ \$ kW/Ano \\
\hline Situação antes & $\mathrm{R} \$ 0,22$ & $\mathrm{R} \$ 6.642,1$ \\
Situção depois & $\mathrm{R} \$ 0,15$ & $\mathrm{R} \$ 5.684,8$ \\
\hline
\end{tabular}

Fonte: Os autores

Dessa forma foi possível uma redução mensal na conta de consumo de energia elétrica de $15 \%$ para os dois tornos usados nessa linha de produção do Fornecedor A. Nessa mesma linha, além da observação do ganho na dimensão econômica é possível calcular o ganho na dimensão ambiental através da contabilidade dos custos ecológicos.

Para esse cálculo foi utilizada a calculadora oficial de créditos de carbono obtida do site do Programa Brasileiro GHG Protocol que tem como principal objetivo o inventário dos gases de efeito estufa pela mensuração e gerenciamento das suas emissões. Na Tabela 4 foram contabilizados os gastos de energia elétrica dos 2 tornos do Fornecedor A durante o ano de 2008, "na situações antes" e "situação depois" da aplicação das práticas de produção enxuta.

Baseados no conceito de contabilidade de custo ecológico foram analisados os dados do Fornecedor A relativos aos resultados obtidos pela implantação das práticas de produção enxuta nas lixadeiras no ano de 2008 descritos na Tabela 5.

Tabela 4 - Consumo e custos diários das lixadeiras para atender a demanda de peças

\begin{tabular}{llll}
\hline Lixadeiras & Peças diárias & Energia diária $(\mathbf{k W})$ & Demanda diária $(\mathbf{R} \$ \mathbf{)}$ \\
\hline Situação antes & 448 & 2115,6 & $\mathrm{R} \$ 104,8$ \\
Situação depois & 582 & 1810,7 & $\mathrm{R} \$ 89,7$ \\
\hline
\end{tabular}

Fonte: Os autores

Através da análise da Tabela 5 verificou-se que com um aumento de demanda de $24 \%$ as práticas da produção enxuta como a padronização da operação e a redução dos desperdícios de movimentação, desperdício de espera e desperdício de retrabalho resultaram em uma diminuição de $15 \%$ no consumo de energia elétrica. 
Tabela 5 - Consumo reduzido de energia elétrica nas lixadeiras após o projeto

\begin{tabular}{lll}
\hline Lixadeiras & Consumo energético (kW/Peça) & Consumo anual (kW/Ano) \\
\hline Situação antes & 2,3 & 558506,6 \\
Situação depois & 1,5 & 478016 \\
\hline
\end{tabular}

Fonte: Os autores

O custo da energia elétrica industrial da CEMIG em 2008 era de $\mathrm{R} \$ 0,40 / \mathrm{KW} / \mathrm{Hora}$ e o consumo das lixadeiras foi calculado pela engenharia de processos do Fornecedor A nas situações antes e depois considerando os modelos das lixadeiras e vida útil no período da atividade do projeto. Consequentemente houve uma redução no valor na conta de energia elétrica como foram descritos na Tabela 6 os valores financeiros acumulados no período de um ano.

Tabela 6 - Custos da energia para produção das peças nas lixadeiras

\begin{tabular}{lll}
\hline Lixadeiras & $\mathbf{R}$ \$ kW/Peça & $\mathbf{R}$ \$ kW/Ano \\
\hline Situação antes & $\mathrm{R} \$ 0,94$ & $\mathrm{R} \$ 27675,4$ \\
Situação depois & $\mathrm{R} \$ 0,62$ & $\mathrm{R} \$ 23686,8$ \\
\hline
\end{tabular}

Fonte: Os autores

Dessa forma foi possível uma redução anual na conta de consumo de energia elétrica de $15 \%$ para as duas lixadeiras usadas nessa linha de produção do Fornecedor A. Nessa mesma linha, além da observação do ganho na dimensão econômica, é possível calcular o ganho na dimensão ambiental através da contabilidade dos custos ecológicos.

$\mathrm{Na}$ Tabela 7 foram contabilizados os gastos de energia elétrica das 2 lixadeiras do Fornecedor A durante o ano de 2008, nas situações antes e depois da aplicação das práticas de produção enxuta. Como as emissões de $\mathrm{CO}_{2}$ são proporcionais à redução de energia, logo também se pode citar que houve uma redução de $15 \%$ quanto à emissão de $\mathrm{CO}_{2}$ em toneladas após a utilização das práticas de Produção Enxuta no Fornecedor A. O valor bruto da redução é de 2,45 toneladas de $\mathrm{CO}_{2}$, o que pode não ter um impacto muito grande, porém, contabilizando todas as linhas de produção, que são 27 linhas similares para atender os seus demais clientes, a redução na emissão de $\mathrm{CO}_{2}$ na atmosfera passa para 66,15 toneladas.

A redução média anual se propagou durante todo o período de estudo para os tornos e lixadeiras usadas nessa linha de produção do Fornecedor A. Na Tabela 7 estão apresentadas as reduções no consumo de energia e nos custos com a sua aquisição no período de 2008 até 2014. A redução média no consumo de energia no período foi de $2803 \mathrm{MW} / \mathrm{ano}$, o que representou a uma redução nos custos com sua aquisição de 118 mil $\mathrm{R} \$ /$ ano, o que pode ser reinvestido na aquisição de novas máquinas e na premiação dos funcionários. As variações na redução do consumo de energia ocorreram devido à variação na demanda anual.

Tabela 7 - Acompanhamento dos resultados do projeto, no período estudado

\begin{tabular}{lccccccccc}
\hline & $\mathbf{2 0 0 8}$ & $\mathbf{2 0 0 9}$ & $\mathbf{2 0 1 0}$ & $\mathbf{2 0 1 1}$ & $\mathbf{2 0 1 2}$ & $\mathbf{2 0 1 3}$ & $\mathbf{2 0 1 4}$ & Total & Média \\
\hline & & & & & & & & & \\
Redução da energia (MW) & $2.694,8$ & 2716,7 & 2962,5 & 2992,0 & 2979,7 & 3249,0 & 2028,2 & 19623,0 & 2803,3 \\
& & & & & & & & & \\
Redução dos custos (mil R\$) & 107,8 & 109,5 & 130,3 & 132,9 & 131,8 & 156,7 & 61,1 & 830,0 & 118,6 \\
\hline
\end{tabular}

Fonte: Os autores

Alimentando a calculadora de créditos de carbono com os dados de redução de energia obtiveram-se os valores anuais de créditos de carbono $\left(\mathrm{t} \mathrm{CO}_{2}\right)$ apresentados na Tabela 8. 
Assim, foi possível quantificar uma redução de 481 toneladas de emissão de $\mathrm{CO}_{2}$ no período de sete anos abordado neste estudo. Isto equivale a uma média de redução de emissão de $\mathrm{CO}_{2}$ de $68,7 \mathrm{t} \mathrm{CO}_{2}$ por ano e, uma provável melhora da qualidade do ar na vizinhança da empresa.

Tabela 8 - Redução nas emissões de $\mathrm{CO}_{2}$ no período estudado

\begin{tabular}{llllllll}
\hline & $\mathbf{2 0 0 8}$ & $\mathbf{2 0 0 9}$ & $\mathbf{2 0 1 0}$ & $\mathbf{2 0 1 1}$ & $\mathbf{2 0 1 2}$ & $\mathbf{2 0 1 3}$ & $\mathbf{2 0 1 4}$ \\
\hline Redução da Energia $(\mathrm{MW})$ & 2.695 & 2.717 & 2.963 & 2.992 & 2.980 & 3.249 & 2.028 \\
\hline Total $(\mathrm{MW} / \mathrm{h})$ & & & & & 19.623 & & \\
\hline Redução das Emissões $\left(\mathrm{t} \mathrm{CO}_{2}\right)$ & 66,02 & 66,56 & 72,58 & 73,30 & 73,00 & 79,60 & 49,69 \\
\hline Total $\left(\mathbf{t ~} \mathbf{C O}_{2}\right)$ & & & & & $\mathbf{4 8 1}$ & & \\
\hline
\end{tabular}

Fonte: Os autores

Assim, foi possível calcular os créditos de carbono que poderiam ser negociados na Bolsa de Valores fornecendo uma receita adicional de: 481( $\left.\mathrm{CO}_{2}\right) * 9,25(\mathrm{US} \$)=\mathrm{US} \$$ $4.449,25$, equivalentes a $\mathrm{R} \$ 16.907,15$ (US $1,00=\mathrm{R} \$ 3,80$ ).

Considerando-se a média anual pode-se atingir uma receita adicional de $\mathrm{R} \$ 2.414,05$ negociando-se estes créditos na bolsa de valores. O valor é baixo, mas a melhora na imagem da empresa, perante a sociedade, pode aumentar a sua carteira de clientes, já que a sociedade está olhando com bons olhos para as empresa que priorizam ao meio ambiente (BENVENGA et al., 2016; MIRANDA et al., 2018).

Para a aplicação da Contabilidade de Custos Ecológicos nos resultados das práticas de Produção Enxuta alguns estágios foram usados para evidencia-los nas três dimensões descritos na Quadro 1.

- Estágio 1: "situação antes": o Fornecedor A estava em uma situação não sustentável, onde muitos dos impactos ambientais não eram identificados e controlados e haviam desperdícios no processo. Nesse estágio havia desperdícios de super processamento, desperdícios de movimentação, desperdícios de sobrecarga e desperdícios de espera na usinagem do Fornecedor A.

- Estágio 2: implantação das práticas de produção enxuta e seus resultados foram mensurados em redução no consumo de energia elétrica.

- Estágio 3: estabilização da produção onde já era possível coletar os ganhos ecológicos.

- Estágio 4: nesse estágio o Fornecedor A seria reconhecido como uma empresa sustentável, pelo balanço dos resultados da contabilidade de custos ecológicos gerando créditos para si mesmo.

No estágio 4 o Fornecedor A já poderia obter ganhos com a redução dos custos com energia de $\mathrm{R} \$ 108$ mil e com a venda de 66 créditos de carbono, equivalentes, respectivamente, a $\mathrm{R} \$ 830$ mil e $481 \mathrm{t} \mathrm{CO}_{2}$ ao final do período estudado. Neste estágio, o Fornecedor A também ganhou com a imagem de uma empresa que toma ações para reduzir impactos no meio ambiente e na sociedade ao seu redor, através da redução de emissões de gases de efeito estufa.

O Quadro 1 sintetiza os resultados da contabilidade de custo ecológico na dimensão econômica, social e ambiental: 
Quadro 1 - Estágios de evolução da sustentabilidade do Fornecedor A

\begin{tabular}{|c|c|c|c|c|}
\hline Dimensão & $\begin{array}{l}\text { Estágio } 1 \\
\text { Ausência de } \\
\text { sustentabilidade }\end{array}$ & $\begin{array}{l}\text { Estágio } 2 \\
\text { Operações } \\
\text { sustentáveis }\end{array}$ & $\begin{array}{l}\text { Estágio } 3 \\
\text { Operações } \\
\text { sustentáveis }\end{array}$ & $\begin{array}{l}\text { Estágio } 4 \\
\text { Completa } \\
\text { Sustentabilidade }\end{array}$ \\
\hline Econômica & $\begin{array}{l}\text { Empresa com } \\
\text { passivos ambientais }\end{array}$ & $\begin{array}{l}\text { Redução de custo } \\
\text { com afastamento } \\
\text { de operadores e } \\
\text { redução no } \\
\text { aumento do de } \\
\text { passivos } \\
\text { ambientais }\end{array}$ & $\begin{array}{l}\text { Redução do valor } \\
\text { da conta de } \\
\text { energia elétrica }\end{array}$ & $\begin{array}{l}\text { Aquisição de } \\
\text { créditos carbono }\end{array}$ \\
\hline Social & $\begin{array}{l}\text { Empresa mal vista } \\
\text { na sociedade por } \\
\text { sobrecarregar a } \\
\text { rede elétrica da } \\
\text { região }\end{array}$ & $\begin{array}{l}\text { Eliminação da } \\
\text { sobrecarga dos } \\
\text { operadores para } \\
\text { evitar } \\
\text { afastamentos } \\
\end{array}$ & $\begin{array}{l}\text { Melhoria na } \\
\text { imagem da } \\
\text { empresa perante a } \\
\text { sobrecarga }\end{array}$ & $\begin{array}{l}\text { Melhora na } \\
\text { qualidade de vida } \\
\text { dos funcionários e } \\
\text { distribuição de } \\
\text { energia elétrica }\end{array}$ \\
\hline Ambiental & $\begin{array}{l}\text { Impactos } \\
\text { ambientais não } \\
\text { conhecidos }\end{array}$ & $\begin{array}{l}\text { Identificação dos } \\
\text { impactos e } \\
\text { definição de ações } \\
\text { para diminuí-los }\end{array}$ & $\begin{array}{l}\text { Redução do } \\
\text { consumo de } \\
\text { energia elétrica } \\
\text { através da } \\
\text { padronização da } \\
\text { operação }\end{array}$ & $\begin{array}{l}\text { Redução do } \\
\text { consumo de } \\
\text { energia elétrica }\end{array}$ \\
\hline
\end{tabular}

Fonte: Os autores

- Na dimensão econômica:

- Cálculo de crédito de carbonos que podem ser negociados na Bolsa de Valores a um valor de $\mathrm{R} \$ 16.907$, no período;

- A melhoria da eficiência do processo produtivo do Fornecedor A através dos ganhos do trabalho padronizado, da redução do tempo de ciclo dos tornos e lixadeiras e diminuição de retrabalho gerando redução de custo e maior margem de lucro para empresa;

- Redução dos custos com aquisição de energia elétrica de $\mathrm{R} \$ 830$ mil, no período. O que contabilizaria como R $\$ 847$ mil em sete anos.

- Na dimensão social:

- Ganhos associados ao seu conceito de redução da sobrecarga do operador, dessa forma, foram eliminados as atividades repetitivas, os esforços físicos do operador, posições não ergonômicas, giros de tronco entre outros, preservando assim, a saúde do operador e contribuindo para que tivessem uma vida saudável.;

- A melhoria da imagem do Fornecedor A através da divulgação da aquisição dos créditos de carbono e da redução dos custos com a aquisição de energia, contribuindo para evitar queda de energia na vizinhança;

- Ao reduzir as emissões de $\mathrm{CO}_{2}$ o Fornecedor A diminui a poluição do ar e em consequência reduz as moléstias causadas pela poluição do ar na comunidade vizinha.

- Na dimensão ambiental:

- Redução no consumo de energia elétrica, alcançando aproximadamente 19.623 MW/ano;

- Devido à dependência de água para a geração de energia, a não utilização do valor energético citado anteriormente, refletiria na diminuição no consumo de água, pela hidroelétrica para gerar tal quantidade de energia.

Desta forma, com a redução de emissões de $\mathrm{CO}_{2}$ se reduz o impacto ambiental 
permitindo que o meio ambiente possa se recuperar devolvendo uma qualidade de vida à população da região.

\section{CONCLUSÕES}

Pelo acima exposto verificou-se que a empresa obteve ganhos sociais devido a redução dos impactos ambientais e da melhoria na qualidade de vida do operador como consequência da redução de esforços físicos em seu processo de produção, fatos que provavelmente levaram à melhora da imagem da empresa.

A empresa pôde ser considerada ecologicamente correta pela redução do consumo de energia elétrica e pela redução da emissão de gases do efeito estufa.

Com a venda dos créditos de carbono e a redução dos custos com a aquisição de energia elétrica houve uma diminuição nos custos totais da empresa no período estudado.

Verificou-se que a venda de $481 \mathrm{t}$ de créditos de carbono pode gerar uma receita adicional de R\$ 16.907 no período considerado, que houve uma redução no consumo de energia elétrica de mais 2.803 mil kW/ano e uma redução nos custos de R \$118.000/ano, demonstrando-se portanto que é possível mesclar as técnicas de produção enxuta com a teoria da contabilidade de custo ecológico de forma a minimizar os impactos sociais e ambientais da empresa, usando soluções economicamente viáveis.

\section{AGRADECIMENTOS}

Os autores agradecem à Universidade Nove de Julho o suporte financeiro ao desenvolvimento da pesquisa.

\section{REFERÊNCIAS}

AHI, Payman; SEARCY, Cory. A comparative literature analysis of definitions for green and sustainable supply chain management. Journal of Cleaner Production, v. 52, p. 329-341, 2013.

ALCOUFFE, S., BERLAND, N., DREVETON, B., Empirical Study of environmental cost, Crises et nouvelles problématiques de la Valeur, p. 1-25, 2010.

ANFAVEA - Associação nacional de fabricantes de veículos automotores, anuário da Indústria automobilística, 1957-2012. 2013. Disponível em : http://www.anfavea.com.br/. Acesso em 18 de Jul. 2018.

BENVENGA, Marco Antônio Campos et al. Genetic algorithm applied to study of the economic viability of alcohol production from Cassava root from 2002 to 2013. Journal of Cleaner Production, v. 113, p. 483-494, 2016.

CHRIST, Katherine L.; BURRITT, Roger L. Material flow cost accounting: a review and agenda for future research. Journal of Cleaner Production, v. 108, p. 1378-1389, 2015.

DERCHI, Giovanni Battista; BURKERT, Michael; OYON, Daniel. Environmental management accounting systems: A review of the evidence and propositions for future 
research. Accounting and Control for Sustainability. In Studies in Managerial and Financial Accounting. Emerald Group Publishing Limited, 2013. v. 26. p. 197-229

DÜES, Christina Maria; TAN Kim Hua; LIM Ming. Green as the new Lean: how to use Lean practices as a catalyst to greening your supply chain. Journal of Cleaner Production, v. 40, p. $93-100,2013$.

ENVIRONMENTAL PROTECTION AGENCY. Valuing Potential Environmental Liabilities for Managerial Decision-Making: A Review of Available Techniques. Office of pollution Prevention and Toxics, Washington, DC, http://www.epa.gov, Acessado em 15 de Julho de 2018.

GALEAZZO, Ambra; FURLAN, Andrea; VINELLI, Andrea. Lean and green in action: interdependencies and performance of pollution prevention projects. Journal of Cleaner Production, v. 85, p. 191-200, 2014.

GIRAÇOL, Juliana et al. Reduction in ecological cost through biofuel production from cooking oils: An ecological solution for the city of Campinas, Brazil. Journal of Cleaner Production, v. 19, n. 12, p. 1324-1329, 2011.

GUNARATHNE, Nuwan et al. Fostering social sustainability management through safety controls and accounting: A stakeholder approach in the mining sector. Accounting Research Journal, v. 29, n. 2, p. 179-197, 2016.

HOLWEG, Matthias., The genealogy of lean production, Journal of Operations Management, v.25, p. 420-437, 2007.

IBGE, Instituto Brasileiro de Geografia e Estatística. Disponível em: http://www.ibge.gov.br/. Acessado em Julho de 2018

MAAS, Karen; SCHALTEGGER, Stefan; CRUTZEN, Nathalie. Reprint of Advancing the integration of corporate sustainability measurement, management and reporting. Journal of Cleaner Production, Special Volume: The Integration of Corporate Sustainability Assessment, Management Accounting, Control, and Reporting. v. 136, Part A, p. 1-4, 2016.

MARIMIN et al. Value chain analysis for green productivity improvement in the natural rubber supply chain: a case study. Journal of Cleaner Production, v. 85, p. 201-211, 2014.

MARKSBERRY, Phillip; BADURDEEN, Fasleena; GREGORY, Bob; KREAFLE, Ken. Management directed kaizen: Toyota's Jishuken process for management development. Journal of Manufacturing Technology Management. 21, 670-686, 2010.

MIRANDA, Amanda Carvalho et al. Analysis of the costs and logistics of biodiesel production from used cooking oil in the metropolitan region of Campinas (Brazil). Renewable and Sustainable Energy Reviews, v. 88, p. 373-379, 2018.

NAKAJIMA, Michiyashu. Environmental management accounting for sustainable manufacturing: Establishing management system of material flow cost accounting (MFCA). Kansai University Review of Business and Commerce, v. 12, p. 41-58, 2010. 
PAMPANELLI, Andrea Brasco; FOUND, Pauline; BERNARDES, Andrea Moura. A Lean \& Green Model for a production cell. Journal of Cleaner Production, v. 85, p. 19-30, 2014.

PASSARINI, Kely Cristina et al. Assessment of the viability and sustainability of an integrated waste management system for the city of Campinas (Brazil), by means of ecological cost accounting. Journal of Cleaner Production, v. 65, p. 479-488, 2014.

PEREIRA, Maria Aparecida. Elaboração e aplicação de instrumento para avaliação da gestão contábil integrada nas dimensões econômica, ambiental e social: uma análise exploratória em empresas do setor sucroalcooleiro do estado de São Paulo. 2011. Dissertação (Mestrado em Engenharia de Produção) - Universidade Nove de Julho, São Paulo, 2011.

PINTO, Geraldo Augusto. O Toyotismo e a mercantilização do trabalho na indústria automotiva do Brasil. Caderno CRH, v. 25, n. 66, p. 535-552, dez. 2012.

RAHANI, A. R.; AL-ASHRAF, Muhammad. Production Flow Analysis through Value Stream Mapping: A Lean Manufacturing Process Case Study. Procedia Engineering, v. 41, p. 1727-1734, 2012.

ROSA, Jorge Marcos et al. Applying of Ecological Cost Accounting in a Textile Industry: A Case Study. Journal of Chemistry and Chemical Engineering, v. 7, p. 251-255, 2013.

SCHALTEGGER, Stefan (Org.). Environmental management accounting for cleaner production. Dordrecht: Springer, 2008. (Eco-Efficiency in Industry and Science, 24).

SILVA FILHO, Silvério Catureba da et al. Environmental and techno-economic considerations on biodiesel production from waste frying oil in São Paulo city. Journal of Cleaner Production, v. 183, p. 1034-1042, maio 2018.

SLACK, Nigel; CHAMBERS, Stuart; JOHNSTON, Robert. Administração da Produção. São Paulo: Atlas, 2009.

VINODH, S.; ARVIND, K. R.; SOMANAATHAN, M. Tools and techniques for enabling sustainability through lean initiatives. Clean Technologies and Environmental Policy, v. 13, n. 3, p. 469-479, 2011.

YIN, Robert K. Estudo de casos: Planejamento e métodos. Bookman, 2010. 